\title{
A MORTE COMO ESPETÁCULO: Michael Jackson agendado e formatado segundo as regras do discurso midiático
}

\author{
Death as a show (spectacle): Michael Jackson set and portrayed \\ according to the rules of the media discourse
}

\section{Rejane de Oliveira Pozobon}

Professora adjunta do Departamento de Ciências da Comunicação da Universidade Federal de Santa Maria (UFSM), pesquisadora do Grupo de Pesquisa Estudos de Jornalismo (CNPq) e do Grupo de Estudos e Pesquisas em Arte, Educação e Cultura (CNPq), Santa Maria, RS - Brasil, e-mail: Rejane.op@terra.com.br

\section{Resumo}

Novas formas de relações sociais e novos modelos de experiência têm sido vivenciados, bem como há uma reconfiguração da vida cotidiana. A soma desses aspectos nos permite dizer que estamos conhecendo (e fundando) uma nova cultura do espetáculo, marcada pelos grandes espetáculos midiáticos e interativos. Este artigo analisa alguns conceitos fundamentais para o entendimento deste contexto e busca, por meio da análise de um acontecimento (espetáculo) recente, refletir sobre o papel que a mídia ocupa no processo de formação da opinião pública e tentar compreender esse novo espaço público, que ganha diferentes contornos a partir do avanço do poder midiático e cujas dinâmicas e processos causam alterações na cultura e rotinas jornalísticas.

Palavras-chave: Cultura do espetáculo. Opinião pública. Mídia. Michael Jackson.

\begin{abstract}
We have lived new forms of social relationships, new models of experience and a new picture of the daily life. The sum of these aspects allows us to say that we are getting to know (and founding) a new culture of show (spectacle), marked by great media and interactive shows. This article analyses some fundamental concepts for the understanding of this concept and tries, through the analysis of a recent event (show), reflect upon the role that the media has concerning the process of the public opinion formation and tried to understand this new public space, which gains new forms from the advance of the mediatic power and whose dynamics and processes cause alterations in jornalistic culture and routines.
\end{abstract}

Keywords: The culture of show (spectacle). Public opinion. Media. Michael Jackson. 


\section{Michael Jackson: o astro, a mídia e o show}

Dia 7 de julho de 2009 será uma data para ser debatida por teóricos e lembrada por gerações. A indústria do entretenimento se voltou para a cobertura de um evento sem precedentes: o último show de Michael Jackson. O espetáculo teve de tudo: artistas famosos, forte apelo dramático e venda das licenças de transmissão. Um entretenimento para ser vendido, consumido e comentado. O fim do limite entre o show e a tragédia.

$\mathrm{Na}$ era do espetáculo, cuidadosamente medida pelas oscilações do Ibope, tem-se nas tragédias humanas um dos principais carros-chefe, e a espetacularização em torno da morte de celebridades é uma delas. A repetição exaustiva de cenas da morte de determinada celebridade garante uma bela audiência, foi assim com Mamonas Assassinas, Princesa Diana, Ayrton Senna, John Lennon, Michael Jackson, e tantos outros.

A mídia sempre acompanhou Michael Jackson. Os recursos tecnológicos e as excentricidades de seus shows e videoclipes não foram os únicos espetáculos da trajetória do rei do pop. Sua vida, assim como sua morte, foi um espetáculo de grande proporção.

$\mathrm{Na}$ verdade, a morte sempre fascinou nossa sociedade. O terrorismo, as pandemias, as grandes catástrofes naturais, tudo é acompanho de perto por uma sociedade ávida por espetáculos ${ }^{1}$. Conforme aponta Arbex (2001), espetacular é a própria sociedade e o espetáculo não consiste apenas nas imagens, mas também nos rituais políticos, religiosos e hábitos de consumo. Segundo o autor, o espetáculo é a soma de tudo aquilo que falta à vida real do homem comum: celebridades, atores, políticos, escândalos - tudo transmite uma sensação de êxtase e permanente aventura.

\section{Opinião pública: quem é e o que quer}

O conceito de opinião pública está presente no desenvolvimento da história da humanidade. Entretanto, o entendimento de opinião pública que se tem atualmente foi se formando ao longo dos tempos e das proposições teóricas de diferentes autores.

Se recuperarmos alguns referentes históricos, veremos que uma das primeiras tentativas de constituição de uma opinião pública remete-se à Idade Antiga, quando Platão tenta lançar mão desta para combater a pederastia. O filósofo pediu aos poetas que representassem esse vício como execrável, criando uma opinião pública sobre o tema.

A Grécia também deu sua contribuição para o conceito. Notável pelo fato de ter refletido a respeito da comunicação humana, a cidade-estado reunia o povo nas praças para definir assuntos de interesse geral, ainda que excluindo mulheres e crianças. Este desenvolvimento da democracia grega, praticada por meio das deliberações dos cidadãos da polis grega, permitia a prática do debate de ideias e, consequentemente, a formação da opinião pública.

Os sofistas, por sua vez, também colaboraram para a formação do conceito de opinião pública ao exercerem a comunicação como prática de poder. Ensinavam técnicas que auxiliavam as pessoas a defenderem o seu pensamento e suas opiniões contrárias. Por desprezarem algumas discussões feitas pelos filósofos, eram chamados de céticos, até mesmo por Sócrates, que se rebelou contra eles dizendo que desrespeitavam a verdade e o amor pela sabedoria.

No período romano também houve contribuição para o conceito. Em um fórum eram decididos os destinos do país. O fórum romano substitui o ágora grego, e a voxpopulli dos romanos correspondia aos cidadãos de Roma com direito a expressar a sua opinião. Já neste período é possível indicar a ideia de espetáculo. Os festivais de dramaturgia e poesia da Grécia e as batalhas sangrentas da Roma Antiga são alguns exemplos desta historicidade.

A Idade Média também nos proporciona uma ampliação do conceito de opinião pública. Os sermões e as cantigas expressavam a voz de uma opinião coesa em torno da fé cristã, quando as multidões se reuniam em praças públicas para a execração dos condenados, um Consensus omminium - acordo de todos - reforçava a ideia das grandes exibições e consolidava a expressão que marcou o período: "A voz

\footnotetext{
1 Neste texto, o conceito de espetáculo é entendido a partir da proposta de Guy Debord (1967), que compreende a ideia que vivemos numa sociedade onde o que importa é a imagem, o espetáculo produzido. Nesta sociedade, a vida perde espaço para a representação da vida, não importando mais o que se faz, como se vive ou como se é, mas como tudo isso é representado e que repercussão essa representação traz na sociedade (opinião pública).
} 
do povo é a voz de Deus", uma tentativa de ocultar o poder hegemônico da Igreja e criar a falsa ideia de que a decisão (opinião) era de um grupo maior.

$\mathrm{Na}$ Idade Moderna, príncipes e reis cultivavam os espetáculos como rituais de seus governos e demonstrações de seus poderes. Maquiavel (O principe) defendia que um governante ou futuro rei deveria prestar atenção à opinião pública. O princípio desta relaçãoé "diga com quem andas, que te direi quem és".

A partir do século XVIII, ficou mais evidente a força da opinião pública e esta passou a ser objeto de análise. Com o surgimento da escola e o aprimoramento de outras instituições que colaboraram para o desenvolvimento cultural, a opinião pública se desenvolveu ainda mais. $\mathrm{Na}$ Inglaterra e na França dos séculos XVIII e XIX, os cafés se popularizaram como polos de disseminação de notícias, debates políticos e crítica literária.

É visível que, depois da Revolução Francesa, a comunicação conheceu outro patamar, graças às conquistas industriais e ao alargamento e aprimoramento dos públicos. Os públicos restritos se transformaram, lentamente, num público aberto, aumentando o seu tamanho e sua importância à medida que o analfabetismo diminuía. Ao mesmo tempo, as atenções não estavam mais centradas nas grandes multidões e passaram a se voltar para as especificidades dos públicos. No início do século XX, o sociólogo Jean Gabriel Tarde, na obra $A$ opinião e as massas, advertia que entrávamos na "era dos públicos" e não mais das massas ou multidões.

Com o passar dos anos, a ascensão da opinião pública vai se relacionando com o desenvolvimento das instituições democráticas, com a diminuição das taxas de analfabetismo e com o destaque que os meios de comunicação vão assumindo. Com o desenvolvimento da mídia, os espetáculos (agora midiáticos) passam a influenciar na trajetória, na sociedade e na cultura contemporânea.

No entanto, o avanço das discussões sobre o conceito não levam a um consenso em relação a ele. As críticas ao conceito de opinião pública proliferam na mesma velocidade que suas revisões são feitas. Bourdieu (1987), por exemplo, não aceita muitos dos entendimentos propostos. Afirma que, sendo a informação um bem de consumo, ela é consumida de maneira desigual. Portanto, a opinião pública seria uma ilusão, já que a sociedade é manipulada pelos sistemas de comunicação que colocam interesses particulares acima dos interesses da sociedade.

\section{Um novo e pluralizado espaço público}

O livre fluxo de informação e o avanço das redes globais de comunicação inviabilizaram a existência de uma esfera pública unificada ${ }^{2}$. Sodré (2009, p. 124) amplia ainda mais essa percepção e afirma que, hoje, o espaço público é "mais do que um lugar de comunicação", é um espaço de "expressão e circulação de forças".

Em suas escritas mais recentes, Habermas faz uma revisão de sua concepção original de esfera pública ${ }^{3}$ e apresenta proposições que nos ajudam a entender o papel dos meios de comunicação na reestruturação (ou reinvenção) do espaço público. Na publicação da $17^{a}$ edição da obra Mudança Estrutural da Esfera Pública, Habermas redige um prefácio intitulado "O Espaço Público, 30 anos depois", no qual afirma a existência de uma pluralidade de esferas públicas. O autor assume que a formação da opinião ocorre em diversas instâncias autônomas de debates. Neste prefácio, Habermas também admite que a obra subestima o potencial crítico dos públicos e apresenta-se demasiadamente pessimista em relação aos meios de comunicação de massa.

Antes dessa revisão, as proposições de Habermas tiveram muitas críticas. Thompson (2000), por exemplo, afirmou que o modelo de Habermas estava preso à concepção tradicional da publicidade como copresença e fechava os olhos para um fato importante que é o distanciamento espaço-temporal, promovido e aprimorado pela mídia.

Esta e outras teorias da área comprovam que a mídia não é o único espaço público, mas é o que oferece maior visibilidade aos temas das outras esferas ou campos sociais ${ }^{4}$. Ao afirmar que, na contemporaneidade, os media cumprem (mesmo que de forma precária) o papel exercido pelas explicações

\footnotetext{
2 Compartilhamos com Wolton (1991) a ideia de que os processos de comunicação levaram à promoção de um "novo espaço público".

3 Entendida anteriormente (1962) como a "rede para a comunicação de conteúdos, tomadas de posições e opiniões, onde os problemas elaborados pelo sistema político encontram eco” (HABERMAS, 2003, p. 188).

4 RODRIGUES, 1990.
} 
míticas e tradicionais das sociedades pré-modernas, Rodrigues (1990) traz a ideia da mídia enquanto propositora de temas sociais.

É fácil constatar que nem todas as vozes estão representadas no espaço de visibilidade midiática. Mesmo assim, a ideia de pensar a mídia como espaço fundamental de mediação não perde a validade.

Ao constituir-se em instituição mediadora dos discursos dos demais campos sociais, a mídia passa a assumir um lugar central na contemporaneidade. A hipótese do agendamento (agenda-setting), formulada por McCombs e Shaw, traduz as sugestões de temas que os meios de comunicação propõem à sociedade e sustenta que a agenda pública acaba se confundindo com a agenda da mídia ${ }^{5}$.

Neste novo espaçopúblico, poderíamos analisar a ideia de espetáculo em diferentes instâncias. Por questão de espaço, nos deteremos a analisar a concepção do espetáculo somente em quatro instâncias: no cinema, na moda, nos programas de entretenimento e no jornalismo.

Não é de hoje que o cinema se tornou um vasto campo de espetáculo. Seus ícones, os filmes hollywoodianos, mostram um mundo de excessos, que vão desde as mega-produções, passando pelos atraentes trailers até chegar aos grandes lançamentos. O mundo da moda também se constitui em um espetáculo do consumo. A massiva divulgação das novas estações promove desfiles altamente elaborados. $\mathrm{O}$ espetáculo da moda diz às pessoas como devem se apresentar e se comportar.

O veículo televisivo, por sua vez, cada vez mais se apresenta como uma sequência de espetáculos. Isso pode ser observado na produção e nos orçamentos milionários das telenovelas e nos programas com forte apelo dramático, sensual e apelativo. Neste item, os exemplos são inúmeros, citemos apenas alguns:
Programa Dr. Hollywood (Rede'TV). O próprio nome do programa já fala por si. As chamadas também chamam a atenção: “A Rede'TV leva vocêpara o mundo dos cirurgiões mais badalados de Berverly Hills", "Descubra o incrível mundo das cirurgias plásticas". "Aqui, os espectadores irão assistir em primeira mão o que acontece nos bastidores desse universo, das pessoas que passam pelas cirurgias aos médicos que vivem esse estilo de vida de Berverly Hills" "Veja todo processo emocional de uma cirurgia plástica, veja os curativos serem removidos e entre na vida de Dr. Hollywood"'. O programa promove a espetacularização das cirurgias plásticas, além de contribuir para a banalização e a exaltação deste ato. Usando a linguagem de reality show, a série faz uma massiva publicização da vida dos pacientes e do médico (no caso, o próprio "Dr. Hollywood", que apresenta os quadros de transformação, mostrando seu "impecável" trabalho).

Programa Esquadrão da Moda (Discovery Home \& Health) ${ }^{7}$. A chamada do programa já anuncia: "A falta de estilo está com os dias contados! Os consultores de moda Stacy London e Clinton Kelly se propõem a "mudar completamente a imagem das pessoas". Cada programa concentra-se em determinada pessoa, indicada por amigos ou familiares como alguém com uma "terrível necessidade de rever seu guarda-roupa". "Armados com as regras, sabendo como mudar o visual e na posse de um cartão de crédito Visa, com limite de 5 mil dólares, é hora de ir às compras".

Somado aos exemplos anteriormente enunciados, é possível ainda citar os inúmeros quadros de "transformação" que circulam nos canais da TV aberta ou por assinatura. Em linhas gerais, os quadros trazem um "antes" eum "depois" e prometem "mudar a vida das felizes selecionadas". No quadro "Um dia de Princesa" (SBT), o apresentador ${ }^{8}$ escolhe uma

\footnotetext{
5 Mais informações sobre a teoria do agendamento, ver TRAQUINA, 2004, 2008.

6 http://www.redetv.com.br/siteredetv/grupos/programas/drhollywood/index.html

7 http://www.discoverybrasil.com/homeandhealth/na-tv/esquadrao-da-moda/. Este programa é tão popular que, neste ano, ganhou uma "versão brasileira" no SBT: http://www.sbt.com.br/esquadraodamoda/oprograma/

8 Trata-se de Netinho de Paula, ex-vocalista do grupo de pagode "Negritude Júnior" e atual vereador da cidade de São Paulo. Além de apresentador, netinho é dono de um canal independente de televisão, a TV da Gente, que seguiu a fórmula da rede americana Black Entertainment Television (BET), cuja grade era feita restritamente por pessoas negras. O canal é transmitido em algumas regiões do Brasil. Em sua página pessoal, Netinho define-se como "uma pessoa preocupada com a população da periferia e que sendo pobres e negros, seriam objeto de discriminação e vítimas da falta de oportunidade para conquistar uma vida melhor". Na web, há também alguns "resumos" da vida do apresentador, salientando sua suposta "luta para melhorar a vida das pessoas mostradas no programa Domingo da Gente, no quadro 'Dia de Princesa', no qual ele aumenta a autoestima de moças que vivem na periferia através de atitudes afirmativas, como tratamento de beleza, doação de dinheiro, cursos de capacitação profissional, etc".http://pt.wikipedia.org/wiki/Netinho_de_Paula
} 
menina para ser "sua princesa". Para ser selecionada, a moça "precisa ter até 25 anos". "Depois disso, já tem de ser rainha", afirma a diretora do programa, Marlene Mattos. O formulário de inscrição ressalta que é importante que a candidata "dedique muito tempo e atenção para escrever sua história, de forma bem comovente e bonita, pois o programa costuma mostrar mulheres e meninas com histórias que podem deixar as pessoas em casa emocionadas"

Mas não podemos pensar que a ideia do espetáculo está restrita aos realities shows, a instância jornalística também age como uma promotora de espetáculos, e a recente morte de Michael Jackson é um exemplo dessa perspectiva.

Alguns aspectos da cobertura midiática exemplificam a espetacularização feita pela mídia. A extensa cobertura do fato, acrescentando pouca informação aos aspectos já abordados e o volume de matérias focadas em detalhes mórbidos, como o estado de decomposição que o corpo estaria por causa do atraso no enterro, são apenas alguns exemplos.

A cobertura do caso não hesitou em reprisar inúmeras vezes a imagem e a fala da filha de Michael Jackson no velório aberto ao público. A partir da declaração de Paris Jackson ${ }^{10}$, a mídia reconstrói a história do menino pobre e negro que, após ser explorado pelo pai durante toda sua infância, faz fortuna e se torna o centro de infinitas polêmicas.

Por fim, a cobertura sobreviveu ao enterro do astro graças à retomada dos escândalos que envolveram a vida do cantor (acusações de pedofilia, brigas na justiça, etc.) e das polêmicas oriundas das dívidas e da fortuna que Michael Jackson deixou.

\section{O triunfo do espetáculo}

Observamos que, nos últimos anos, a mídia possibilitou uma ampliação e, ao mesmo tempo, uma multiplicação dos espetáculos, por meio de processos mais atraentes e interativos. "O espetáculo, como tendência a fazer ver o mundo que já não se pode tocar diretamente, serve-se da visão como o sentido privilegiado da pessoa humana, o que em outras épocas fora o tato" (DEBORD, 1997, p. 18).
Partindo do princípio de ser a potencialidade do fato se enquadrar nos "critérios de noticiabilidade" (WOLF, 2002) do veículo o que agenda a mídia, é possível afirmar que o agenda-setting é um mecanismo concreto de pré-seleção noticiosa e também um condicionante do espaço público e da formação da opinião pública.

Os media não são veículos neutros de informação, fazem um enquadramento dos temas que noticiam e nem sempre conseguem trazer a pluralidade de fontes necessária à cobertura jornalística. Mas, o que faz um acontecimento virar notícia? Por que somente alguns poucos eventos são selecionados para ganhar o status de notícia? Por que alguns acontecimentos são notícia para determinados meios enquanto em outros os mesmos fatos não são sequer mencionados? O que leva um fato a ser percebido como relevante?

Os fatos podem passar despercebidos por não ter um enquadramento que permita ser observado como um acontecimento notável? Muitas dessas perguntas ainda compõem o cenário teórico do campo da comunicação. Algumas começam a ser respondidas, outras ainda são objeto investigativo de muitos pesquisadores da área.

É inegável a importância que os medias assumem ao agendar os acontecimentos com direito a existência pública, fazendo com que passem a compor os principais temas de debate na esfera pública. Ao mesmo tempo em que agenda os acontecimentos, a mídia também propõe-lhes um significado, oferecendo interpretações e formas específicas para seu entendimento.

Wolf (2002) utiliza o conceito de noticiabilidade para descrever os atributos necessários para que um acontecimento se torne notícia. Segundo o autor, a noticiabilidade pode ser definida como o conjunto de requisitos exigidos dos acontecimentos para que eles possam garantir o direito à existência pública. A partir dessa proposição, podemos dizer que a noticiabilidade é construída por meio de um conjunto de valores dados às notícias, tais como: excepcionalidade, sensacionalismo, ausência de ambiguidade, etc.

\footnotetext{
9 <http://www.rebelado.com/beleza-e-moda/inscricao-um-dia-de-princesa-show-da-gente-netinho-sbt/>

10 "Desde que eu nasci, o papai foi o melhor pai que vocês podem imaginar. Eu só queria dizer que eu o amo muito".
} 
Em tempos de espetacularização, o sensacionalismo é um ingrediente importante da construção noticiosa. Mostrar mulheres que conseguem emagrecer em tempo recorde, transformar-se em uma semana ou ganhar respeito e aceitação na aquisição de um novo guarda-roupa faz parte desta receita.

Entretanto, seria demasiadamente simplificador tentar entender a seleção das notícias somente como uma escolha pessoal do jornalista ou do meio que este representa. Trata-se de uma questão muito mais ampla, que acontece ao longo do processo produtivo, em que uma diversidade de critérios, normas, valores e rituais acabam se relacionando com a própria noticiabilidade dos fatos.

Importa ressaltar também que um dos critérios de noticiabilidade está associado à função mediadora da mídia (RODRIGUES, 1990). Ao assumir o papel estratégico de apresentar/divulgar os fatos anunciados pelas demais instituições, a mídia aponta as estratégias de noticiabilidade que as instituições devem lançar mão para se adequar às exigências do campo midiático. A mídia deixa, então, de somente intermediar vozes e falas e passa a selecionar, interferir, ganhando um poder de decisão que, de alguma forma, foi outorgado pelas demais instituições.

A mídia expõe seus critérios de noticiabilidade e as pessoas produzem acontecimentos que se encaixam perfeitamente nesses critérios. A cerimônia de despedida de Michael Jackson foi um show cuidadosamente produzido para se enquadrar nas regras e nas estratégias do discurso midiático, englobando todos os ingredientes que um espetáculo precisa conter para emocionar, problematizar e ganhar espaço de discussão na esfera pública.

\section{REFERÊNCIAS}

ARBEXJr., J. Showrnalismo: a notícia como espetáculo. São Paulo: Casa Amarela, 2001.

BOURDIEU, P. A opinião pública não existe. In: THIOLLENT, M. Crítica metodológica, investigação social e enquete operária. 4. ed. São Paulo: Polis, 1987. p. 137-151.

DEBORD, G. A sociedade do espetáculo: Rio de Janeiro: Contraponto, 1997.
HABERMAS,J.Mudança estrutural da esfera pública: Rio de Janeiro: Tempo Brasileiro, 2003.

RODRIGUES, A. D. Estratégias da comunicação: questão comunicacional e formas de sociabilidade. Lisboa: Presença, 1990.

SODRÉ, M. A narração do fato: notas para uma teoria do acontecimento. Petrópolis: Vozes, 2009.

TARDE, G. A opinião e as massas. São Paulo: Martins Fontes, 1992.

THOMPSON,J.B.Amídia e a modernidade. Petrópolis: Vozes, 2000.

TRAQUINA, N. Teorias do jornalismo: porque as notícias são como são. Florianópolis: Insular, 2004.

A tribo jornalística: uma comunidade interpretativa transnacional. 2. ed. Florianópolis: Insular, 2008.

WOLF, M. Teorias da comunicação. 7. ed. Lisboa: Presença, 2002.

WOLTON, D. Lês contradictions de l'espace public médiatisé. Revista Hermes, n. 10, p. 95-114, 1991.

Recebido: 20/08/2009

Received: 08/20/2009

Aprovado: 05/10/2009

Approved: 10/05/2009

Revisado: 15/01/2010

Reviewed: 01/15/2010 